\title{
Bioavailability of IgG Administered by the Subcutaneous Route
}

\author{
Melvin Berger • Stephen Jolles • Jordan S. Orange • \\ John W. Sleasman
}

Received: 21 December 2012 / Accepted: 30 January 2013/Published online: 1 March 2013

(C) The Author(s) 2013. This article is published with open access at Springerlink.com

\begin{abstract}
Purpose US licensing studies of subcutaneous IgG (SCIG) calculate dose adjustments necessary to achieve area under the curve (AUC) of serum IgG vs. time on SCIG that is noninferior to that on intravenous IgG (IVIG), within the FDAset limit of $\pm 20 \%$. The results are interpreted as showing that different SCIGs differ in bioavailability. We used three approaches to determine if the bioavailabilities were actually different.

Methods Dose adjustments and AUCs from published licensing studies were used to calculate bioavailabilities using the formula: Bioavailability ( $\%$ of IVIG) $=$ AUC (SCIG) $\div$ AUC(IVIG) x 1/Dose Adjustment. We also compared the increment in serum IgG concentration achieved with varying doses of SCIG in recent meta-analyses with the increment with different doses of IVIG, and determined the serum $\operatorname{IgG}$ concentrations when patients switched SCIG products at the same dose.

Results The actual bioavailabilities were: Gamunex ${ }^{\circledR} 65.0 \%$, Hizentra ${ }^{\circledR} 65.5 \%$, Gammagard ${ }^{\circledR} 67.2 \%$, Vivaglobin ${ }^{\circledR}$
\end{abstract}

M. Berger $(\square)$

CSL Behring LLC, King of Prussia, PA 19406, USA

e-mail: mel.berger@cslbehring.com

S. Jolles

Department of Medical Biochemistry and Immunology,

University Hospital of Wales, Cardiff, UK

J. S. Orange

Texas Children's Hospital, Section of Immunology Allergy

and Rheumatology, Baylor College of Medicine,

Houston, TX, USA

J. W. Sleasman

Department of Pediatrics, University of South Florida,

St. Petersburg, FL, USA
$69.0 \%$. Regression analyses of serum IgG vs. dose showed that the mean increase in serum IgG resulting from a $100 \mathrm{mg} / \mathrm{kg} / \mathrm{month}$ increment in SCIG dosing was $69.4 \%$ of the increase with the same increment in IVIG dosing $(84 \mathrm{mg} / \mathrm{dL}$ vs. $121 \mathrm{mg} / \mathrm{dL})$. Patients switching SCIG preparations at the same dose had no change in serum IgG levels, confirming that bioavailabilities of the SCIG preparations did not differ.

Conclusions Decreased bioavailability appears to be a basic property of SCIG and not a result of any manufacturing process or concentration. Because serum IgG levels do not vary with different SCIG products at the same dose, adjustments are not necessary when switching products.

Keywords Subcutaneous IgG (SCIG) · bioavailability $\cdot \operatorname{IgG}$ dose adjustments $\cdot$ intravenous IgG (IVIG)

\section{Introduction}

Because of uncertainty about which pharmacokinetic parameter: peak, trough or mean serum $\mathrm{IgG}$ concentration, if any, should be matched when switching patients with primary immune deficiencies (PID) from intravenous $\operatorname{IgG}$ (IVIG) to subcutaneous IgG (SCIG), the US Food and Drug Administration (US FDA) requires matching the area under the curve (AUC) of serum IgG vs. time on SCIG to that of IVIG [1]. Adjusting the dose to achieve the same AUC is considered necessary because of presumed differences in the bioavailability of IgG and similar proteins when given by the intramuscular (IM) or subcutaneous (SC) routes as compared with the intravenous (IV) route [2]. Dose adjustments of $120 \%$ to $153 \%$ have been used in different studies of polyclonal SCIG, implying that the different products have different bioavailabilities [3-6]. However, "non-inferiority" 
designs, which accept a margin of $\pm 20 \%$ of AUC, have been employed, so the derived dose adjustments may not reflect the actual bioavailability of different products [1]. This, in turn, might suggest that different manufacturing processes alter the $\operatorname{IgG}$ molecules in different ways or that more highly concentrated IgG solutions might behave differently than less concentrated solutions, and that dose adjustments may be necessary when switching from one SCIG product to another. This study was carried out to determine if, in fact, different SCIG preparations differ in bioavailability.

SCIG is commonly used as replacement therapy in patients with PID [3-8]. It has also been successfully tried in autoimmune peripheral neuropathies [9]. Unlike IVIG, SCIG initially forms a local depot and reaches the blood stream indirectly through the lymphatic system, which significantly slows down the absorption of IgG into the circulation [10]. Several studies suggest that the bioavailability of subcutaneously administered monoclonal antibodies, Fc fusion proteins and polyclonal $\operatorname{IgG}$ may be reduced due to degradation by tissue enzymes and/or non-covalent binding to structural proteins of the extracellular matrix [2].

In spite of the lower bioavailability of SCIG compared with IVIG, switching from IVIG to SCIG may be beneficial for some patients, because SCIG administration: (i) overcomes specific obstacles to the use of IVIG, such as the requirements for venous access, trained personnel, and specialized facilities; (ii) allows more even distribution of doses over time to avoid "wear-off" effects such as malaise, fatigue, arthralgias/myalgias, and increased susceptibility to infections towards the end of each dosing interval; and (iii) provides freedom from infusion-related systemic adverse events [7, 8]. In Europe, the IVIG monthly dose is usually divided into four equal weekly doses when patients are switched from IVIG to SCIG [11, 12]. However, the US FDA requires that the monthly dose of SCIG be adjusted to provide equivalent total monthly systemic exposure to $\mathrm{IgG}$ on SCIG as compared with the previous IVIG therapy, as assessed by AUC of serum IgG concentration over time [1].

Here we report the bioavailabilities of different individual SCIG products calculated from the actual pharmacokinetic data, rather than just the apparent dose adjustments necessary to achieve AUCs within the $80 \%$ margin accepted as meeting the FDA's criterion of "non-inferiority" [3-6]. The results show that all SCIG products have remarkably similar bioavailabilities. We also compared the mean slopes of the lines of serum $\operatorname{IgG}$ vs. dose from large meta-analyses of SCIG and IVIG studies and found that the ratio of those slopes very closely approximates the results from the individual SCIG licensing studies. Finally, to confirm the conclusions that different SCIG products have similar bioavailabilities, we compared serum IgG levels in PID patients who switched from one SCIG product to another at the same dose, and found that the serum IgG levels did not change. Together, the results suggest that: (i) decreased bioavailability is a general property of $\operatorname{IgG}$ when it is administered by the SC as compared to the IV route, (ii) different SCIG products have similar bioavailabilities, and, thus, (iii) dose adjustments are not necessary when switching between SCIG products.

\section{Methods}

In order to calculate the bioavailabilities of Hizentra ${ }^{\circledR}(20 \%)$, Vivaglobin ${ }^{\circledR}(16 \%)$, Gamunex ${ }^{\circledR}(10 \%)$, and Gammagard ${ }^{\circledR}$ $(10 \%)$, we extracted data on the mean dosage adjustment, AUC achieved with SCIG ( $\mathrm{AUC}_{\mathrm{SCIG}}$ ) on that adjusted dose, and $\mathrm{AUC}$ on IVIG $\left(\mathrm{AUC}_{\mathrm{IVIG}}\right)$ from published reports of US licensing trials in which PID patients already on stable IVIG treatment regimens were switched to SCIG [3-6]. The mean ratios between the $\mathrm{AUC}_{\mathrm{SCIG}}$ and the $\mathrm{AUC}_{\mathrm{IVIG}}$ were used to calculate SCIG bioavailabilities using the formula:

$$
\begin{aligned}
\text { Bioavailability }(\% \text { of } I V I G)= & \left(A U C_{S C I G} \div A U C_{I V I G}\right) \\
& \times 1 / \text { Dose Adjustment }
\end{aligned}
$$

Data from a meta-analysis reporting the relationship between mean serum IgG trough levels and monthly IVIG doses in 17 different studies which together included 676 PID patients on 14 different IVIG products were obtained from Orange, et al. [13]. Data from a meta-analysis reporting the relationship between steady-state serum IgG concentrations and total monthly doses of SCIG in 9 different studies, which together included 376 PID patients on 8 different products, were obtained from Orange et al. [14]. The slopes of the lines of linear regression analyses for each route of therapy were compared to determine the ratio of the mean increment in serum IgG per $100 \mathrm{mg} / \mathrm{kg} /$ month increment in IgG dose. This ratio was then taken as an estimate of the relative bioavailability of SCIG as compared to IVIG. In the IVIG meta-analysis [13], the majority of patients had either common variable immune deficiency (CVID; $49.3 \%$ ) or X-linked agammaglobulinemia (XLA; $37.4 \%$ ). The mean age in individual studies varied from 2.3 years to 44 years. Underlying PID diagnoses were not listed in the SCIG pooled analysis, but it is likely that the predominant diagnoses were also CVID and XLA. All studies included in both meta-analyses had durations of at least 6 months. In both analyses, a linear dependency between trough serum IgG concentrations and $\operatorname{IgG}$ doses was observed $[13,14]$.

Finally, pharmacokinetic data from two prospective, open-label studies conducted mainly in the European Union (EU) and in the US, respectively, were used to calculate the changes in serum IgG levels in PID patients switching between different SCIG products. In the EU study [15], 19 
patients previously treated with stable weekly SCIG infusion regimens (13 patients on Vivaglobin ${ }^{\circledR}, 4$ patients on Subcuvia ${ }^{\circledR}[16 \%]$ and 2 patients on Gammanorm $\left.{ }^{\circledR}[16 \%]\right)$ were switched to an equal dose of Hizentra ${ }^{\circledR}$ (mean $[ \pm$ standard deviation; SD] of individual median doses: $120 \pm 36 \mathrm{mg} / \mathrm{kg} /$ week). Serum IgG levels were measured immediately before infusions during three visits 3 to 6 months prior to switching to Hizentra ${ }^{\circledR}$, at Weeks 1,4 , 8, 16 after switching to Hizentra ${ }^{\circledR}$ and every 4 weeks thereafter. The mean IgG levels were calculated for each patient for the wash-in/wash-out period (Weeks 1-8), the steadystate efficacy period (Weeks 16-24), and for the postefficacy period (Weeks 30-36), to be sure that a steady state was achieved. The mean serum IgG levels were calculated by averaging individual patient's median values at each time period. In the US study [16], 19 patients receiving steadystate Vivaglobin ${ }^{\circledR}$ treatment were switched to an equal weekly dose of Hizentra ${ }^{\circledR}$. Due to dose rounding in several cases, the mean $( \pm \mathrm{SD})$ dose of Hizentra ${ }^{\circledR}$ was 1.04 times higher than that of Vivaglobin ${ }^{\circledR}: 155 \pm 60 \mathrm{mg} / \mathrm{kg} /$ week vs. $150 \pm 60 \mathrm{mg} / \mathrm{kg} /$ week. Serum IgG levels were measured 8 weeks before switching to Hizentra ${ }^{\circledR}$ (Week 0), before the last infusion of Vivaglobin ${ }^{\circledR}$ (Week 8), and twice after the switch to Hizentra ${ }^{\circledR}$ (Weeks 12 and 24). In these studies, no dose adjustments were made after switching to Hizentra ${ }^{\circledR}$. All measurements were performed in a single CLIA-certified laboratory.

\section{Results}

Data extracted from the US licensing studies of SCIG preparations [3-6] is summarized in Table I. The dose adjustments used in the various studies were $137 \%$ to $153 \%$ and the ratios for $\mathrm{AUC}_{\mathrm{SCIG}} / \mathrm{AUC}_{\mathrm{IVIG}}$ actually achieved ranged from 0.890 to 1.002 . The bioavailabilities relative to IVIG of the four SCIG preparations were calculated from these data using the formula provided in Methods.

The results for all four SCIG preparations were very similar: Hizentra ${ }^{\circledR} 65.5 \%$; Gammagard ${ }^{\circledR} 67.2 \%$; Gamunex ${ }^{\circledR}$ $65.0 \%$; and Vivaglobin ${ }^{\circledR} 69.0 \%$ (Table I). The mean bioavailability of these SCIG products was thus $66.7 \%$ of IVIG, with a SD of only $\pm 1.8 \%$ (Fig. 1).

To further study the bioavailability of a broader range of different SCIG preparations as compared to a broader range of IVIG preparations, we compared the slopes of linear regression lines for serum IgG vs. dose in recent meta-analyses of all available IVIG and SCIG studies [13, 14]. The results are presented in Fig. 2 (upper panels). The slope for the mean increase in serum IgG levels resulting from a $100 \mathrm{mg} / \mathrm{kg} / \mathrm{month}$ increment in the SCIG dose $(84 \mathrm{mg} / \mathrm{dL}$ per $100 \mathrm{mg} / \mathrm{kg} / \mathrm{month})$ was lower than the slope of the line of the mean increase in trough serum IgG levels achieved with the same increment of IVIG doses (121 mg/dL per $100 \mathrm{mg} / \mathrm{kg} /$ month) $[13,14]$. In striking similarity with the bioavailabilities calculated from the four US licensing studies, the ratio of these slopes was $69.4 \%$, suggesting that this bioavailability is directly related to the SC route of administration and not to specific properties of any individual SC or IV preparation.

Based on the above results, we hypothesized that since the bioavailabilities of different SCIG products were actually similar, switching between different SCIG products would not result in changes in the steady-state serum IgG levels, despite the different dose adjustments suggested by their licensing studies. To test this hypothesis, we analyzed steady-state serum IgG levels in two studies of PID patients switched from other SCIG products to the same dose of Hizentra $^{\circledR}$. In the EU study [15], PID patients $(n=19)$ on stable

Table I Bioavailabilities of SCIG products

\begin{tabular}{|c|c|c|c|c|}
\hline SCIG product & Vivaglobin ${ }^{\circledR}$ & Hizentra ${ }^{\circledR}$ & Gamunex ${ }^{\circledR}$ & Gammagard $®$ \\
\hline Reference & $\begin{array}{l}\text { Berger } \mathrm{M} \text { et al. } \\
2011[3]\end{array}$ & $\begin{array}{l}\text { Berger M et al. } 2011 \text { [3] } \\
\text { Wasserman RL et al. } 2011 \text { [4] }\end{array}$ & $\begin{array}{l}\text { Wasserman RL } \\
\text { et al. } 2010 \text { [5] }\end{array}$ & $\begin{array}{l}\text { Wasserman RL } \\
\text { et al. } 2011[6]\end{array}$ \\
\hline Total number of patients, $\mathrm{n}$ & 24 & 18 & 26 & $35^{\mathrm{a}}$ \\
\hline Patients with CVID, n (\%) & $18(75)$ & $17(94)$ & $\mathrm{n} / \mathrm{a}$ & $27(58)^{\mathrm{b}}$ \\
\hline Age in years, median (range) & $35(9-61)$ & $38.5(10-60)$ & $\mathrm{n} / \mathrm{a}(13-75)$ & $\mathrm{n} / \mathrm{a}(14-77)$ \\
\hline Reported $\mathrm{AUC}_{\mathrm{SCIG}} / \mathrm{AUC}_{\mathrm{IVIG}}$ ratio & 0.945 & 1.002 & 0.890 & $0.922^{\mathrm{a}}$ \\
\hline SCIG dose adjustment, $\%$ of IVIG dose & 137.0 & 153.0 & 137.0 & $137.3^{\mathrm{a}}$ \\
\hline $\begin{array}{l}\text { Dose adjustment required to yield } \\
\mathrm{AUC}_{\mathrm{SCIG}} / \mathrm{AUC}_{\mathrm{IVIG}}=1.00^{\mathrm{c}}\end{array}$ & 145.0 & 152.7 & 153.9 & 148.9 \\
\hline Bioavailability, $\%$ of IVIG & 69.0 & 65.5 & 65.0 & 67.2 \\
\hline
\end{tabular}

$A U C$ area under the curve; IVIG intravenous IgG; $n$ number of patients; $n / a$ not available; SCIG subcutaneous IgG

${ }^{\mathrm{a}} \geq 12$-year-old patients only

${ }^{\mathrm{b}}$ All treated patients $(n=47)$

${ }^{\mathrm{c}}$ Calculated as: (SCIG dose adjustment, $\%$ of IV dose $) \div\left(\right.$ Reported $\mathrm{AUC}_{\mathrm{SCIG}} / \mathrm{AUC}_{\mathrm{IVIG}}$ ratio) 


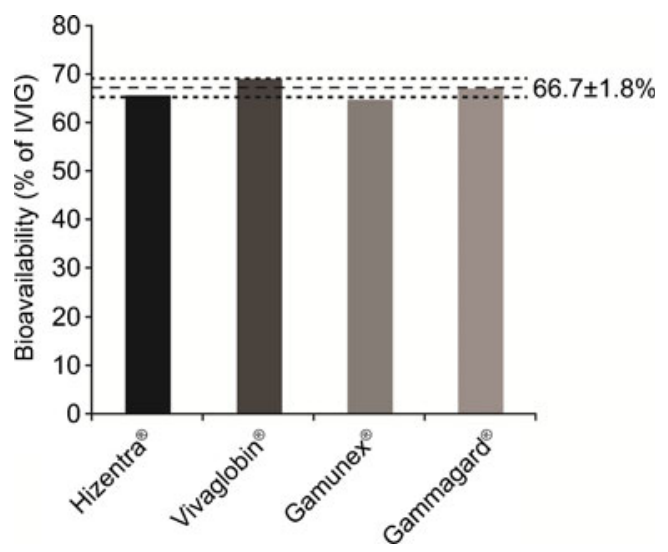

Fig. 1 Actual bioavailabilities of SCIG products. Bioavailabilities of Hizentra $^{\circledR}$, Vivaglobin ${ }^{\circledR}$, Gamunex ${ }^{\circledR}$, and Gammagard ${ }^{\circledR}$ are shown. The mean bioavailability of the four SCIG products is shown with a horizontal dashed line. Horizontal dotted lines represent SD

dosing regimens with Vivaglobin ${ }^{\circledR}(n=13)$, Subcuvia ${ }^{\circledR}(n=4)$, or Gammanorm ${ }^{\circledR}(n=2)$ at a mean monthly dose of $120 \pm$ $36 \mathrm{mg} / \mathrm{kg} /$ week were switched to the same weekly dose of Hizentra ${ }^{\circledR}$. The overall mean $( \pm \mathrm{SD})$ serum IgG levels on the other SCIG products was $850 \pm 140 \mathrm{mg} / \mathrm{dL}$, while on Hizentra ${ }^{\circledR}$ it was $830 \pm 120 \mathrm{mg} / \mathrm{dL}$ (a difference of only $2.4 \%$; Fig. 3). The mean $( \pm \mathrm{SD})$ steady-state serum IgG levels were $820 \pm 140 \mathrm{mg} / \mathrm{dL}$ to $850 \pm 120 \mathrm{mg} / \mathrm{dL}$ during the different stages of the Hizentra ${ }^{\mathbb{R}}$ treatment period. The mean change in serum $\mathrm{IgG}$ concentrations on Hizentra ${ }^{\circledR}$, relative to the previous SCIG products was $-20 \mathrm{mg} / \mathrm{dL}(95 \% \mathrm{CI}:-49 \mathrm{mg} / \mathrm{dL}$ to $+90 \mathrm{mg} / \mathrm{dL})$. In the US study [16], 19 patients on a mean weekly dose of $150 \pm 60 \mathrm{mg} / \mathrm{kg}$ of Vivaglobin ${ }^{\circledR}$ were switched to Hizentra ${ }^{\circledR}$ at a mean weekly dose of $155 \pm 60 \mathrm{mg} / \mathrm{kg}$. The $4 \%$ increase in dose on Hizentra ${ }^{\circledR}$ was due to rounding in a few cases. The overall mean $( \pm \mathrm{SD})$ serum $\operatorname{IgG}$ levels on Vivaglobin ${ }^{\circledR}$ and Hizentra ${ }^{\circledR}$ were not different $(1150 \pm 270 \mathrm{mg} / \mathrm{dL}$ vs. $1130 \pm 270 \mathrm{mg} / \mathrm{dL}$; a difference of only $1.7 \%, p=$ NS; Fig. 4). The mean $( \pm S D)$ serum IgG levels were $1160 \pm 290 \mathrm{mg} / \mathrm{dL}$ and $1100 \pm 250 \mathrm{mg} / \mathrm{dL}$ at Weeks 12 and 24 of the study (4 and 16 weeks after the last Vivaglobin ${ }^{\circledR}$ dose), respectively. The mean change of serum $\mathrm{IgG}$ concentration during the Hizentra ${ }^{\circledR}$ treatment, relative to the Vivaglobin ${ }^{\circledR}$ treatment, was $-20 \mathrm{mg} / \mathrm{dL}(95 \% \mathrm{CI}$ : $-83 \mathrm{mg} / \mathrm{dL}$ to $+43 \mathrm{mg} / \mathrm{dL}$ ). The absence of a statistically significant change in serum IgG levels after switching from other SCIG preparations to Hizentra ${ }^{\circledR}$ (the $95 \%$ CI included 0 in both studies) allowed us to exclude the possibility that there are differences in the bioavailabilities of different SCIG preparations that are statistically or clinically significant.

\section{Discussion}

We present three lines of evidence which together suggest that different commercial preparations of SCIG have very similar bioavailabilities relative to that of IVIG. First, we calculated actual bioavailabilities from available data obtained in studies in which different dose adjustments were used when switching from IVIG to SCIG to achieve the target AUC established with IVIG [3-6]. Because the study designs accepted "non-inferiority" with a margin of $\pm 20 \%$ of this target, dose adjustments of $137 \%$ have been accepted in some product labels, which resulted in only $89 \%$ of the target AUC $[3,5,6]$. In contrast, the one licensing study in which the $\mathrm{AUC}_{\mathrm{SCIG}}$ actually reached $100 \%$ of the target suggested that a dose adjustment of $153 \%$ was necessary with that product [4]. When the actual AUCs achieved with the different adjusted doses are taken into account, it is readily apparent that all of the preparations licensed for SCIG use in the US have bioavailabilities within the range $65.0-69.0 \%$ as compared to IVIG.

Next, we compared data from recent meta-analyses which estimated the mean increase in serum $\operatorname{IgG}$ levels achieved with increments in the dose of $\operatorname{IgG}$ given to PID patients $[13,14]$. Together, these analyses contain data from 26 studies, which included 1052 patients treated with 22 different IgG products. The results show that the mean increase in the serum IgG concentrations with any given increment in the $\mathrm{IgG}$ dose differs if the $\operatorname{IgG}$ is being given by the $\mathrm{SC}$ as opposed to the IV route. The mean increase in steady-state serum $\operatorname{IgG}$ level for every $100 \mathrm{mg} / \mathrm{kg} / \mathrm{month}$ increment in SCIG dose is $69.4 \%$ of the increase in trough level achieved with the same increment in the IVIG dose (Fig. 2). Interestingly, although many more products and patients, and a broader range of doses were included in these meta-analyses than in the individual licensing studies, this result closely matches the bioavailabilities of each of the four individual preparations presented above (mean: $66.7 \%$ of IVIG; Table 1). Furthermore, the individual licensing studies as well as the meta-analyses indicate that the bioavailabilities of the highly concentrated SCIG preparations, Vivaglobin ${ }^{\circledR}$ and Hizentra ${ }^{\circledR}$, do not differ from those for $10 \%$ IV products when given by the SC route. The reduction in bioavailability observed when the same $10 \%$ preparations are given by the SC route vs. the IV route also supports the conclusion that changes in the bioavailability are not related to differences in the concentrations (within the range of $10 \%$ to $20 \% \mathrm{IgG}$ ) or other specific characteristics of the individual products. Thus, although labeling of different SCIG products in the US implies that their bioavailabilities are different, the discrepancies arise from the fact the licensing studies used "non-inferiority" designs in which any $\mathrm{AUC}_{\mathrm{SCIG}} / \mathrm{AUC}_{\mathrm{IVIG}}$ ratio equal to or above $80 \%$ was acceptable. As a result, dose adjustments recommended in the US FDA-approved labels range from $137 \%$ to $153 \%$ of the monthly IVIG dose [3-6]. Indeed, true AUC equivalence $\left(\mathrm{AUC}_{\mathrm{SCIG}} / \mathrm{AUC}_{\mathrm{IVIG}} \geq 1\right)$ was only achieved in one of the four studies [4]. 

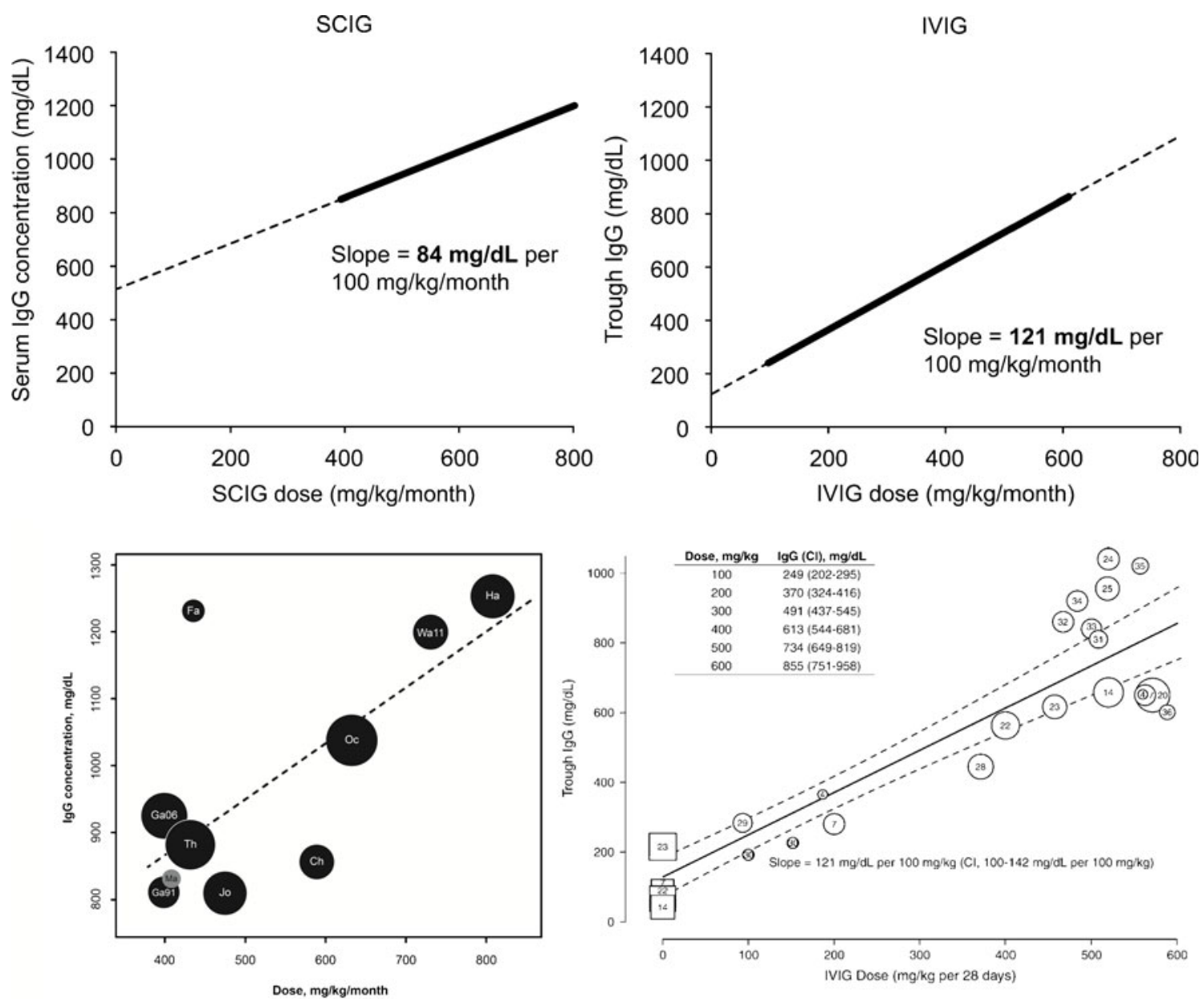

SCIG bioavailability $=84 \mathrm{mg} / \mathrm{dL} \div 121 \mathrm{mg} / \mathrm{dL}=69.4 \%$ of IVIG

Fig. 2 Linear regression analyses of correlation between IgG doses and trough serum IgG concentration in SCIG- and IVIG-treated PID patients. Linear trendlines representing the dose-related increase in trough serum IgG levels in SCIG- and IVIG-treated PID patients are shown at the same scale to enable comparison (top row). Previously published analyses are also presented at the original scale (bottom row). The thick lines represent the portions of the trendlines

Taken together, the above results suggested the hypothesis that, if the bioavailabilities of different SCIG products are the same, the serum IgG concentrations should not change when patients switch from one SCIG preparation to another at the same dose. This hypothesis was tested in two prospective studies, which indeed showed only minimal, clinically irrelevant changes in the serum IgG levels when patients were switched from other preparations to Hizentra ${ }^{\circledR}$.

Although differences in the kinetics of uptake of IgG into the circulation following SC vs. IV injection were reported more than 100 years ago [17], the reasons for the apparent decrease in overall bioavailability remain unclear. Decreases in bioavailability similar to those reported here have also been reported for therapeutic monoclonal antibodies and $\mathrm{Fc}$ fusion proteins $[18,19]$. Although one previous study [7] corresponding to the data in the original figures. Slope values in $\mathrm{mg} / \mathrm{dL}$ per $100 \mathrm{mg} / \mathrm{kg} / \mathrm{month}$ are indicated next to the trendlines. One retrospective SCIG study data (Ma; gray circle) was excluded from the trendline calculation, the others were all prospective. Original figures were reproduced with permission from Orange et al., 2012 [14] and Orange et al., 2010 [13]. The formula used to estimate average SCIG bioavailability is shown below the graphs

suggested that the bioavailability of SCIG might be lower in obese patients with high body mass index (BMI), subsequent studies have not confirmed that [3-6]; and a reanalysis showed that the apparent correlation between bioavailability and BMI was due to inclusion of a few individuals with extremely low or high BMI [3,4]. All these observations suggest that the apparent decrease in bioavailability is an intrinsic property of $\operatorname{IgG}$ when it is presented by the SC rather than the IV route, and is not due to alterations introduced by the purification or production processes of any preparation, the concentration of the IgG or the specificity of the antibodies. We speculate that degradation of IgG by extracellular proteases, non-covalent binding to the extracellular matrix, and/or altered access to endothelial cell neonatal $\mathrm{Fc}$ receptor $(\mathrm{FcRn})$, may all contribute to the 


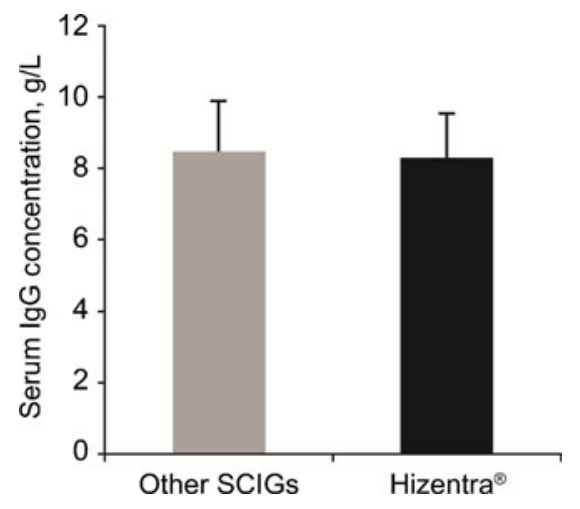

Fig. 3 Serum IgG levels reported in an EU study in PID patients switched from other SCIG products to equivalent doses of Hizentra ${ }^{\circledR}$. Mean $(n=19)$ serum IgG concentration measured 3-6 months before switching from other SCIG products (Vivaglobin ${ }^{\circledR}$, Subcuvia ${ }^{\circledR}$ or Gammanorm ${ }^{\circledR}$ ) to Hizentra ${ }^{\circledR}$ was not different from that measured during 16 weeks of Hizentra ${ }^{\circledR}$ treatment. Error bars represent SD

decreased bioavailability reported for SCIG as compared to IVIG [2].

In the last few years, many publications have reported that switching from IVIG to home-based SCIG therapy was safe, improved the quality of life for PID patients, and had overall efficacy equal to that of IVIG [7-9, 11, 20]. The US FDA has chosen to use the AUC as a standard for comparison of SCIG with IVIG and of different SCIG products with each other. However, most physicians use the trough serum $\mathrm{IgG}$ concentration, obtained just before an $\mathrm{IgG}$ dose, as the preferred pharmacokinetic parameter for evaluating and adjusting IgG doses. This may be based on the logic that the total serum IgG level is the sum of individual specific antibody levels, and the latter determine protection against new infection at any point in time. Efficacy-dose relationships for both IVIG and SCIG show that, in general, higher

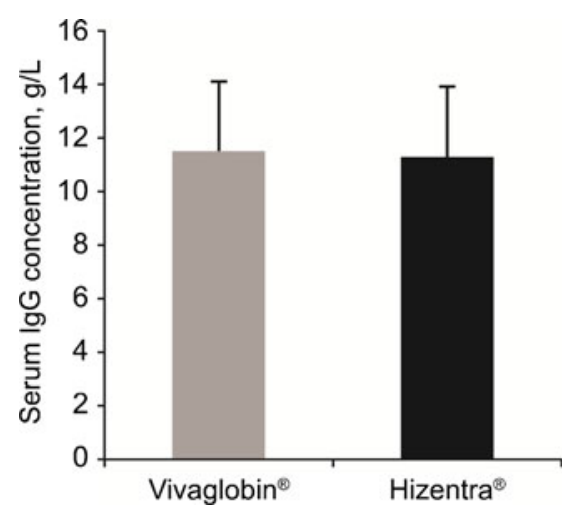

Fig. 4 Serum IgG levels reported in a US study in PID patients switched from subcutaneous Vivaglobin ${ }^{\circledR}$ to an equivalent dose of Hizentra ${ }^{\circledR}$. Mean $(n=19)$ serum IgG concentration measured during Vivaglobin ${ }^{\circledR}$ therapy was not different from that measured during 40 weeks after switching to Hizentra ${ }^{\circledR}$. Error bars represent SD doses result in higher serum IgG levels and increased freedom from infection, the major goal of therapy in PID [13, 14, 23]. These studies all focus on the mean results for groups of patients. However, closer inspection of the results of any individual study reveals wide variation in the relationship between serum IgG levels and doses of IgG in different individual patients with both SC and IV routes of $\operatorname{IgG}$ therapy $[1,20]$. Examination of the relationships between SCIG and IVIG doses and serum IgG levels suggest that, in general, a monthly dose of SCIG equal to the monthly dose of IVIG will result in a steady-state IgG level on SCIG approximately $13 \%$ higher than the trough IgG level on IVIG [3, 21]. Conversely, the steady-state serum IgG level on SCIG will be approximately equal to the trough IgG level on IVIG when the monthly dose of SCIG is $50 \%$ of the previous monthly IVIG dose [3,22]. It should be noted however, that the trough $\operatorname{IgG}$ level represents the lowest serum IgG concentration during any IVIG dosing interval, and that in most studies of IVIG efficacy, the mean IgG concentration during any given dosing interval is considerably higher than the trough at the end of that interval. The mean level across the whole dosing interval, in turn, is reflected in the AUC. Data on efficacy as a function of AUC, per se, is not yet available. However, there are data which suggest that higher steady- state IgG levels on SCIG, which would correspond to higher AUC values, are associated with fewer infections and decreased morbidity [14, 23]. Recent studies have clearly shown that different individual PID patients require different serum IgG concentrations to remain free from infection [24, 25]. Individualization of dosing is thus important regardless of which route of therapy is preferred for any given PID patient, but differences in bioavailability do not suggest a preference for one preparation of SCIG over another.

\section{Conclusions}

In conclusion, our results strongly suggest that decreased bioavailability appears to be a basic property of SCIG and not a result of any manufacturing process or concentration. Because serum IgG levels do not vary with different SCIG products at the same dose, adjustments are not necessary when switching products.

Acknowledgments This study was supported by CSL Behring. The editorial assistance of PHOCUS Services GmbH, part of the Fishawack Group of Companies, supported by CSL Behring is acknowledged.

Disclosure of Conflicts of Interests Dr Berger is a salaried employee of CSL Behring with equity interests; Dr Jolles reports clinical trial support from CSL Behring, Baxter, and Octapharma and consultant fees from CSL Behring, BPL, Baxter and Octapharma; Dr Orange is a consultant to Baxter, Talecris Biotherapeutics and CSL Behring, a member of the review panel for Octapharma and a member of the 
advisory board for IBT reference laboratories; Dr Sleasman reports consultant fees and clinical trial support from CSL Behring. No other potential conflicts of interest were reported.

Open Access This article is distributed under the terms of the Creative Commons Attribution License which permits any use, distribution, and reproduction in any medium, provided the original author(s) and the source are credited.

\section{References}

1. Aebersold P. Regulatory requirements for subcutaneous Ig for PID. In: Intravenous immunoglobulins in the 21 st century: progress and challenges in efficacy, safety and paths to licensure. FDA workshop. 2005. http://www.fda.gov/downloads/BiologicsBloodVaccines/ NewsEvents/WorkshopsMeetingsConferences/TranscriptsMinutes/ UCM054437.pdf. Accessed 8 Nov 2012.

2. Wang W, Wang EQ, Balthasar JP. Monoclonal antibody pharmacokinetics and pharmacodynamics. Clin Pharmacol Ther. 2008;84:548-58.

3. Berger M, Rojavin M, Kiessling P, Zenker O. Pharmacokinetics of subcutaneous immunoglobulin and their use in dosing of replacement therapy in patients with primary immunodeficiencies. Clin Immunol. 2011;139:133-41.

4. Wasserman RL, Melamed I, Nelson RP, et al. Pharmacokinetics of subcutaneous IgPro20 in patients with primary immunodeficiency. Clin Pharmacokinet. 2011;50:405-14.

5. Wasserman RL, Irani AM, Tracy J, et al. Pharmacokinetics and safety of subcutaneous immune globulin (human), $10 \%$ caprylate/ chromatography purified in patients with primary immunodeficiency disease. Clin Exp Immunol. 2010;161:518-26.

6. Wasserman RL, Melamed I, Kobrynski L, et al. Efficacy, safety, and pharmacokinetics of a $10 \%$ liquid immune globulin preparation (GAMMAGARD LIQUID, $10 \%$ ) administered subcutaneously in subjects with primary immunodeficiency disease. J Clin Immunol. 2011;31:323-31.

7. Ochs HD, Gupta S, Kiessling P, Nicolay U, Berger M. Safety and efficacy of self-administered subcutaneous immunoglobulin in patients with primary immunodeficiency diseases. J Clin Immunol. 2006;26:265-73.

8. Hagan JB, Fasano MB, Spector S, et al. Efficacy and safety of a new $20 \%$ immunoglobulin preparation for subcutaneous administration, IgPro20, in patients with primary immunodeficiency. J Clin Immunol. 2010;30:734-45.

9. Lucas M, Hugh-Jones K, Welby A, et al. Immunomodulatory therapy to achieve maximum efficacy: doses, monitoring, compliance, and self-infusion at home. J Clin Immunol. 2010;30 Suppl 1: S84-9.

10. Bonilla FA. Pharmacokinetics of immunoglobulin administered via intravenous or subcutaneous routes. Immunol Allergy Clin North Am. 2008;28:803-19. ix.

11. Hoffmann F, Grimbacher B, Thiel J, Peter HH, Belohradsky BH. Home-based subcutaneous immunoglobulin G replacement therapy under real-life conditions in children and adults with antibody deficiency. Eur J Med Res. 2010;15:238-45.

12. Gardulf A, Nicolay U, Asensio O, et al. Rapid subcutaneous IgG replacement therapy is effective and safe in children and adults with primary immunodeficiencies-a prospective, multi-national study. J Clin Immunol. 2006;26:177-85.

13. Orange JS, Grossman WJ, Navickis RJ, Wilkes MM. Impact of trough $\mathrm{IgG}$ on pneumonia incidence in primary immunodeficiency: a meta-analysis of clinical studies. Clin Immunol. 2010;137:21-30.

14. Orange JS, Belohradsky BH, Berger M, et al. Evaluation of correlation between dose and clinical outcomes in subcutaneous immunoglobulin replacement therapy. Clin Exp Immunol. 2012;169: $172-81$.

15. Jolles S, Bernatowska E, de Gracia J, et al. Efficacy and safety of Hizentra ${ }^{\mathbb{R}}$ in patients with primary immunodeficiency after a doseequivalent switch from intravenous or subcutaneous replacement therapy. Clin Immunol. 2011;141:90-102.

16. Nguyen D, Dorsey T, Alberdi C, Duff J, Sleasman JW. Subcutaneous Hizentra $^{\circledR}(20 \%)$ is better tolerated and shares similar efficacy compared to subcutaneous Vivaglobin ${ }^{\circledR}$ (16\%). J Allergy Clin Immunol. 2012;129:AB15.

17. von Behring E. Serum therapy in therapeutics and medical science. Nobel lecture. 1901. http://nobelprize.org/nobel_prizes/medicine/ laureates/1901/behring-lecture.html. Accessed 27 Nov 2012.

18. Emu B, Luca D, Offutt C, et al. Safety, pharmacokinetics, and biologic activity of pateclizumab, a novel monoclonal antibody targeting lymphotoxin alpha: results of a phase I randomized, placebo-controlled trial. Arthritis Res Ther. 2012;14:R6.

19. Zhou H. Clinical pharmacokinetics of etanercept: a fully humanized soluble recombinant tumor necrosis factor receptor fusion protein. J Clin Pharmacol. 2005;45:490-7.

20. Abolhassani H, Sadaghiani MS, Aghamohammadi A, Ochs HD, Rezaei N. Home-based subcutaneous immunoglobulin versus hospital-based intravenous immunoglobulin in treatment of primary antibody deficiencies: systematic review and meta analysis. J Clin Immunol. 2012.

21. Desai SH, Chouksey A, Poll J, Berger M. A pilot study of equal doses of $10 \%$ IGIV given intravenously or subcutaneously. J Allergy Clin Immunol. 2009;124:854-6.

22. Thepot S, Malphettes M, Gardeur A, et al. Immunoglobulin dosage and switch from intravenous to subcutaneous immunoglobulin replacement therapy in patients with primary hypogammaglobulinemia: decreasing dosage does not alter serum IgG levels. J Clin Immunol. 2010;30:602-6.

23. Berger M. Incidence of infection is inversely related to steady-state (trough) serum IgG level in studies of subcutaneous IgG in PIDD. J Clin Immunol. 2011;31:924-6.

24. Bonagura VR, Marchlewski R, Cox A, Rosenthal DW. Biologic IgG level in primary immunodeficiency disease: the $\mathrm{IgG}$ level that protects against recurrent infection. J Allergy Clin Immunol. 2008; $122: 210-2$.

25. Lucas M, Lee M, Lortan J, et al. Infection outcomes in patients with common variable immunodeficiency disorders: relationship to immunoglobulin therapy over 22 years. J Allergy Clin Immunol. 2010;125:1354-60. 